\title{
Tres visiones sobre el río Mapocho
}

\author{
Carolina Katz Profesora, Pontificia Universidad Católica de Chile \\ Paul Reid Arquitecto, Pontificia Universidad Católica de Chile \\ Martín Andrade Director Ejecutivo, Fundación Mi Parque \\ fotografía Carolina Katz, Martín Andrade
}

La búsqueda de una real puesta en valor del río Mapocho es el tema común de los tres autores. Katz aborda el problema desde un punto de vista vivencial, mientras que Reid lo enfrenta desde la perspectiva de su contaminación y morfología. Finalmente, Andrade plantea una propuesta de revalorización e integración del paisaje desde su realidad natural.

“SANTIAGUINOS: NECESITAMOS QUERER NUESTRO RÍO MAPOCHO" / ¿Valora usted el río Mapocho y su paisaje, como un patrimonio a respetar, cuidar y disfrutar? La mayoría de los santiaguinos considera nuestro río feo y sucio; ni habitantes, ni autoridades lo valoran tal como es: un torrente cambiante estacionalmente, rodeado de un paisaje agreste de espinos, de sauces, de álamos, de pastos nativos, de dedales de oro, de grandes piedras, que permite vistas magníficas a la cordillera y a los atardeceres. No podemos apreciarlo porque no sabemos verlo; en su lugar quisiéramos ver un río navegable similar a otros cauces de agua de grandes capitales desarrolladas, pero el Mapocho no es así.

No obstante -y bajo ninguna circunstancia- el hecho que no lo sepamos apreciar justifica la destrucción de su ámbito, emprendida por los propios ciudadanos. Desde hace más de cien años el río ha sufrido importantes daños: es alcantarillado, basural y espacio disponible para infraestructuras viales y equipamientos, las que ocupan su cauce y bordes sin mayor respeto ni cuidado a su carácter. El río Mapocho y su paisaje forman un ecosistema único y valioso para nuestros habitantes, ciudad y cultura: el entendimiento y cuidado de su lógica hídrica, flora, fauna y la diversidad de su paisaje son esenciales al momento de preservar el equilibrio ecológico de la cuenca de Santiago.

Urgen una visión, entendimiento, comprensión y toma de posesión de este complejo paisaje, que permitan una ocupación apropiada tanto a su naturaleza como a las demandas de la ciudad que lo rodea.

Para los autores contemporáneos Augustin Berque ${ }^{1}$ y Javier Maderuelo ${ }^{2}$, la relación entre paisaje y ser humano es íntima e inseparable y conforma la cultura. El concepto paisaje se entiende como un constructo cultural, indivisible del ojo humano, cargado de interpretaciones; a su vez, el paisaje forma culturalmente al hombre que está inmerso en él. Cómo se entiendan los paisajes, se emprenderá su construcción.

A la luz de estos autores, aparece la pregunta sobre la real capacidad de ver el paisaje del río Mapocho. ¿Se está realmente mirando e interviniendo este paisaje como un lugar único con carácter propio, como un lugar preponderante en la cultura santiaguina? ¿Es el Mapocho un territorio que se intenta rescatar desde una perspectiva sustentable que lo proteja, o sólo se ve como espacio disponible para todo lo que no cabe tan fácilmente en otra parte de la ciudad? Es más, Roger Brunet y Robert Ferras (1992) afirman que "el paisaje revela las tensiones y las contradicciones de las sociedades. Los paisajes que creamos son el reflejo del valor que otorgamos a los diferentes componentes de nuestros contextos". En la realidad global, invadida por una valoración principalmente económica del entorno y de las relaciones que con él se establecen, muchos elementos del paisaje - en especial aquellos más locales y propios- han pasado a segundo plano; en su lugar, predominan otros fenómenos culturales. Este hecho en parte se explica porque muchos de los paisajes que estamos construyendo son ambiguos y pobres (aunque a veces pertenezcan a las comunas más ricas del país), frutos de una contemplación y mirada equivocada que no ha sabido insertarse, ni participar, ni crear desde el entorno cultural, físico, social y económico que nos corresponde. Al contrario, la mayor parte de las veces sólo hemos querido imponer una concepción de paisaje
The search for placing a set value for the Mapocho River is the common theme among the three authors. Katz approaches the problem from the experiential point of view, while Reid confronts it from the perspective of its contamination and morphology. Lastly, Andrade suggests a proposal of revalorization and integration of the landscape from its natural reality.

importada de otras realidades, con todas las contradicciones que esto produce sobre un entorno ajeno.

Hoy las imágenes de paisajes se han multiplicado y descontextualizado, perdiendo los vínculos con sus culturas de origen y su relación desde y con el ser humano; fuera de sus contextos ya no pueden ser nombradas como paisajes, son sólo imágenes. No es posible construir paisajes sólo con imágenes exportadas y elegidas desde la infinitud de medios que las publican; sólo se están emulando entornos sin un vínculo de pertenencia.

El desarrollo tiene que ver con entender el propio territorio, su carácter y posibilidades para poder incorporarlos y disfrutarlos con una mirada sustentable. Hoy se ha emprendido la tarea de descontaminar las aguas del río Mapocho al año 2009: esta es una oportunidad para volver a mirar el río como valor y apoyar su desarrollo como fuente de riqueza urbana y agrado. ARQ

Carolina Katz

LUGAR DE CONFLUENCIAS / Con sus $110 \mathrm{~km}$ de largo y una cuenca de $4.230 \mathrm{~km}^{2}$, el río Mapocho baja torrentosamente desde una altura de $1.159 \mathrm{msnm}$, desembocando en el río Maipo a $252 \mathrm{msnm}$. Configura y da soporte al valle que cobija a la ciudad de Santiago, una ciudad que actualmente cabe seis veces y media en su cuenca. A lo largo de $40 \mathrm{~km}$, conecta 16 comunas y une el sector poniente de la ciudad al oriente. La confluencia de aguas recogidas por el río difiere de la dispersión que actualmente encontramos en sus riberas: dicha dispersión responde a una serie de problemas que requieren ser abordados con atención y cuidado respondiendo a los más básicos principios urbanos. La polución, el abandono del cauce y la fragmentación del espacio asociado a este constituyen tres grandes problemas arrojados por una primera aproximación al río. Sin duda, el primer y mayor de estos asuntos dice relación con la contaminación de sus aguas: la gran transformación del lecho del Mapocho ocurrida a fines del s. xvIII y su paulatina incorporación al sistema de alcantarillado de la ciudad produjo durante años el deterioro de la actividad de delicados ecosistemas asociados a él. La desaparición de gran parte de la vida acuática y la falta de agua para recreación, con contacto directo o sin él, hacen de esta una de las dificultades más grandes al momento de recuperar aquella cercanía que gozara la ciudad en sus orígenes. No sólo la contaminación de las aguas ha significado un alejamiento en la relación con el río: la descarga de escombros y desperdicios en sus riberas, trasladada a la periferia de la ciudad, ha contribuido a una contaminación constante por percolación de líquidos y elementos en descomposición, contribuyendo a una contaminación continua en el tiempo.

El abandono del cauce constituye un segundo frente al momento de hacerse cargo de un territorio llamado a ser recorrido y reconocido. "El paisaje se vuelve patrimonio de quien lo percibe y vive, reconociendo sus diversas escalas desde el nivel macroterritorial hasta el particular tangible y su totalidad a través de la visión, del recorrido y de la experiencia histórica y física de cada hombre o lugar (...) del ojo y del pie" (Gosselin, 2007). El reconocimiento del territorio requiere la suma de experiencias que lleven a transformar este espacio en un lugar 
1 Augustin Berque (1942) geógrafo y orientalista francés.

2 Javier Maderuelo (1950), doctor

en Arquitectura y doctor en Historia

del Arte español.

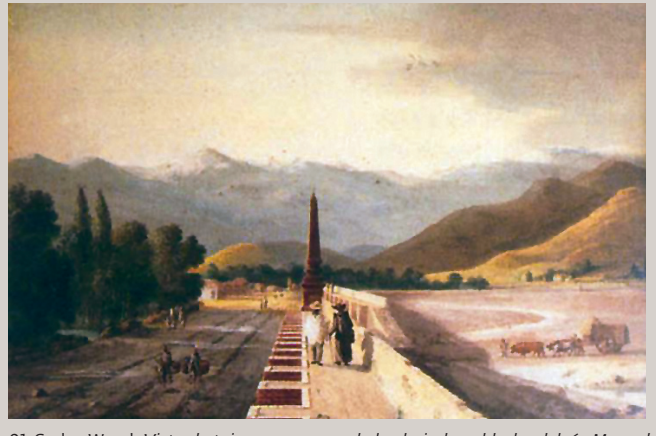

01 Carlos Wood. Vista de tajamar con una de las bajadas al lecho del río Mapocho. Óleo sobre tela, s. xix. Fuente: Guarda, Gabriel. Joaquín Toesca. El arquitecto de Moneda. 1752 - 1799. Ediciones Universidad Católica, Santiago, 1997

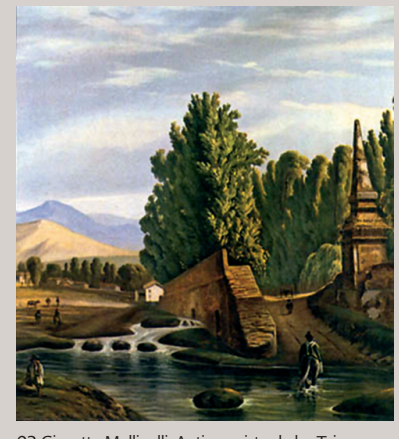

02 Giovatto Mollinelli. Antigua vista de los Tajamares siglo XIX. Fuente: Archivo Carolina Katz.

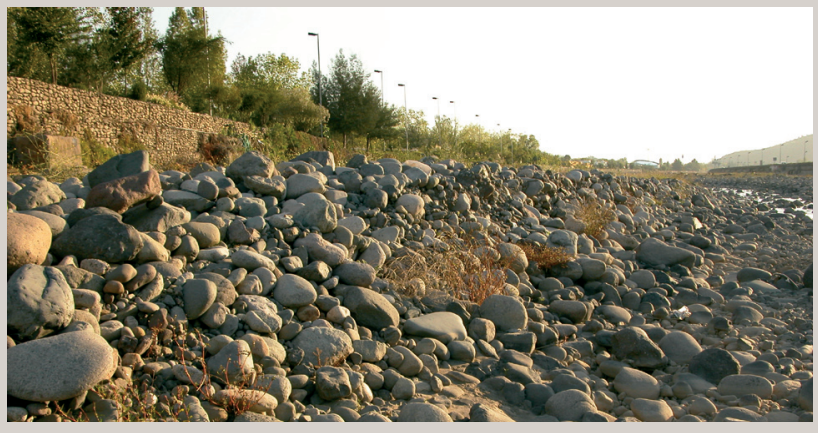

03 Lecho del río Mapocho, Vitacura. Fuente: Archivo Carolina Katz.

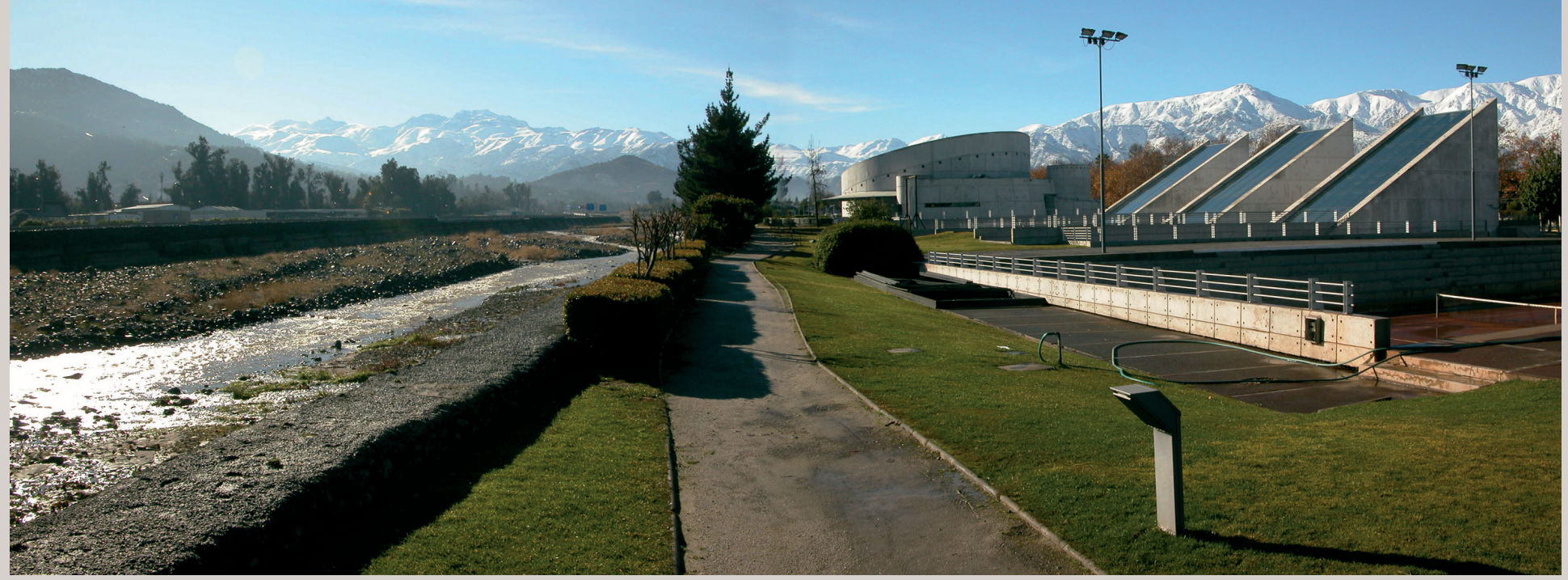

04 Vista rivera sur hacia el oriente, altura Lo Arcaya, Vitacura. Fuente: Archivo Carolina Katz

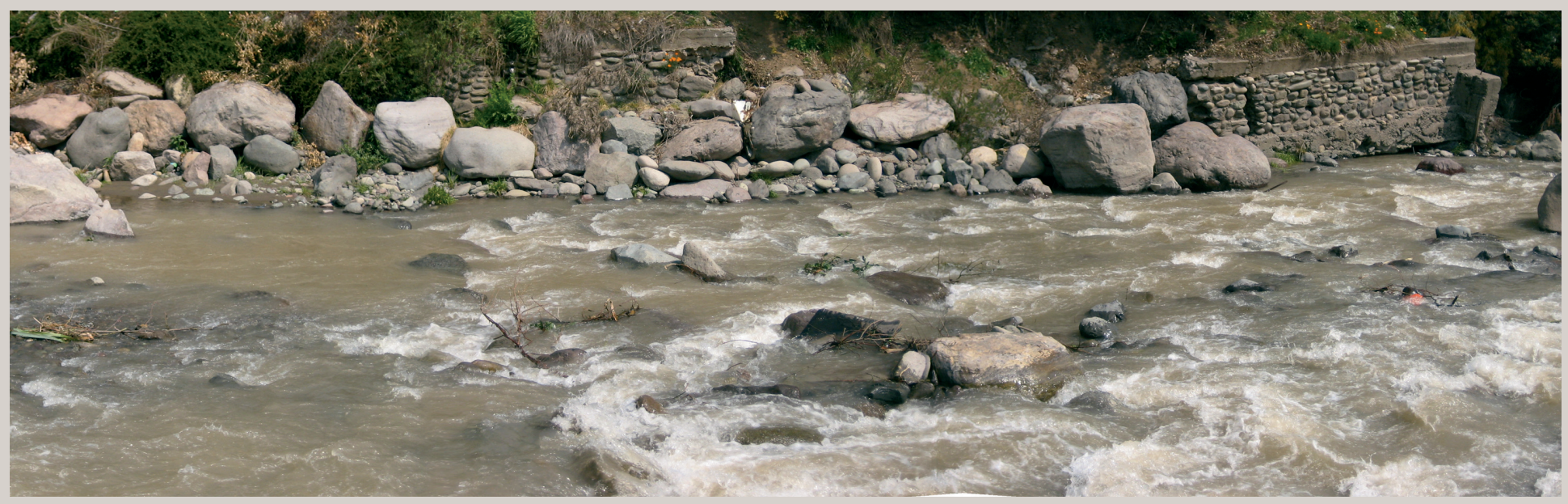

05 Torrente con características propias, El Arrayán, Santiago. Fuente: Archivo Carolina Katz 


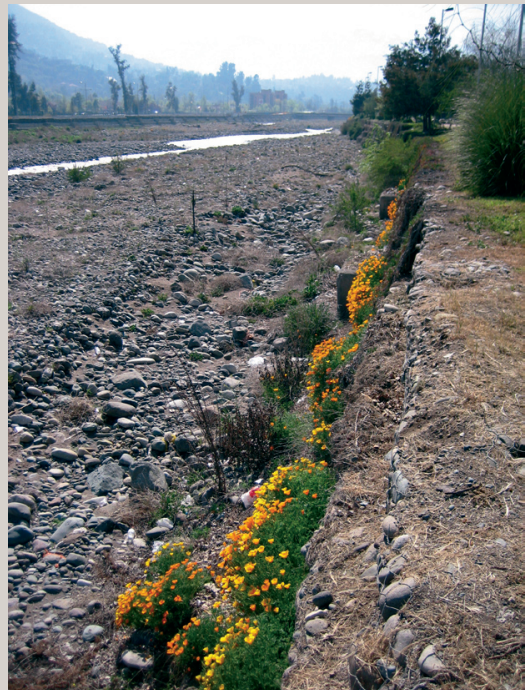

06 Vegetación en zonas protegidas. Fuente: Archivo M. Andrade

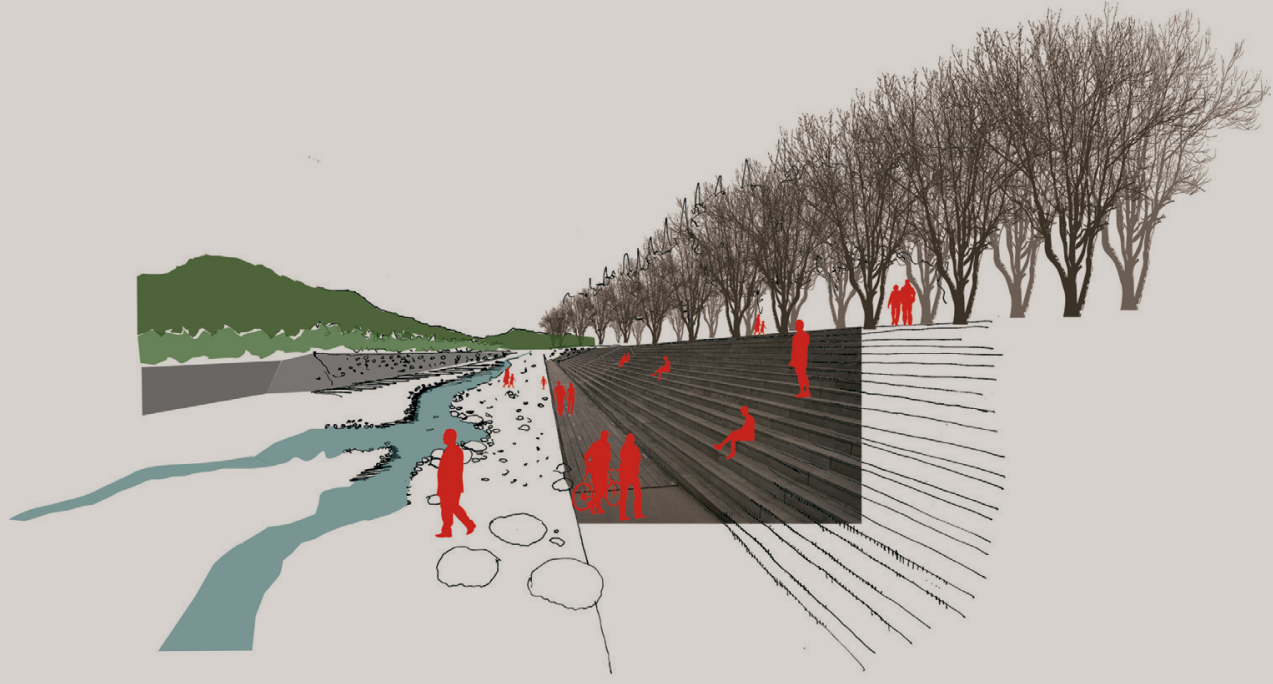

07 a 09 Proyecto de título, Martín Andrade, 2007 representativo; reconocer y valorar el cauce es parte de la impresión de significado otorgada por cada uno de los habitantes al momento de experimentar un lugar cargado de sentido.

La fragmentación del espacio del río ha llevado con el tiempo a enfrentarnos a una sucesión de riberas con distintas formas de tratamiento: la desagregación de dichos tramos o fragmentos atenta contra la experimentación de un espacio en continuas conexiones. El reconocimiento del río como un lugar supone la identificación de un espacio que guarda características únicas y que, como tal, es reconocido y valorado por los ciudadanos. Resulta claro que cualquier esfuerzo que se haga en función de recuperar la continuidad perdida del río, queda sin efecto si no se incorpora una valorización de este espacio desde los propios habitantes. Tal como recuerdan los geógrafos Romero y Vásquez: "un espacio que aumentando en sus habitantes los sentidos de lugar, pertenencia e identidad, conduzca a incrementar los niveles de participación y responsabilidad en su cuidado y preservación".

No hace tanto, los urbanistas del Plan Regulador Intercomunal de Santiago de 1960 (Pavez, 2007) proponían para el espacio del río el rol de corredor ecológico, una intención que ha sido rescatada en planes reguladores subsiguientes. Sin embargo, en la actualidad dicho espacio se ve amenazado por la falta de continuidad frente un territorio que actualmente ya se presenta fragmentado. El río Mapocho es depositario de una serie de características y cualidades dignas de ser consideradas desde la perspectiva de una urbanidad atenta a lo concreto y sensorial (De Solá Morales, 2005): un reconocimiento de esas cualidades animaría a la experimentación de un espacio rico en relaciones, que actualmente se dispersa en un sinnúmero de decisiones inconexas. Otorgarle al río un orden claro, que reconozca y valore sus cualidades, es labor no sólo de urbanistas y arquitectos, sino de cualquier santiaguino que reconozca en este espacio una oportunidad de compromiso con el paisaje que le rodea. ARq

Paul Reid

REVALORIZACIÓN DEL PAISAJE DEL RÍO MAPOCHO. PROYECTO DE TítULO / Durante los últimos años el tramo oriente del río Mapocho, específicamente a lo largo de la comuna de Vitacura, se ha visto transformado con la incorporación de una serie de programas y actividades en sus bordes, las que en su mayoría tienen una nula o muy mala relación con ellos deteriorando enormemente la apreciación de su paisaje. El río y sus bordes se presentan como una sumatoria de partes y programas que conviven por mera casualidad espacial y están lejos de conformar un proyecto continuo y coherente. Las calidades y cualidades desde el punto de vista espacial y paisajístico no han sido tratadas apropiadamente, dejando muchas veces a la caja del río en un rol de patio de trasero de la ciudad, con grandes indefiniciones desde su escala, límites y paisaje.

El proyecto propuesto intenta recuperar el valor del río como patrimonio urbano y como parte íntegra del paisaje. A través de una estrategia general y sistemática, capaz de responder a las particularidades de cada sector, se busca producir un correcto enlace entre las dinámicas de la ciudad y el espacio del río, conformando un sistema complejo de piezas en la ciudad donde el Mapocho juegue un rol fundamental desde el punto de vista espacial, del paisaje y del programa.

El objetivo del proyecto es revalorizar el río y su patrimonio espacial, histórico y paisajístico: no sólo para sanearlo sino también para transformarlo en un lugar atractivo de visitar y recorrer, único dentro de la ciudad.

Se trabajan cuatro puntos:

Su curso de agua y su comportamiento hídrico. El río Mapocho no es un río navegable como el Sena ni el Támesis; es un torrente.

La vegetación, las quebradas que llegan al río y el material del lecho. Estos elementos hoy aparecen de manera informal y casual. La intervención busca formalizarlos, ordenarlos y realzarlos para constituir un paisaje cualificado y con carácter.

El carácter de río urbano y patrimonio de la ciudad. Con su gran extensión y ancho continuo el río puede ser ocupado no sólo en sus bordes sino también en su interior, conteniendo posibles programas temporales.

Sus bordes. Se propone complementar e integrar dentro de la trama de la ciudad las riberas como espacios de calidad, de esparcimiento para sus habitantes y parte integral de un sistema de áreas verdes metropolitano y comunal.

En palabras de Rafael Moneo (1995), se intenta plantear un proyecto "(...) que pertenezca al lugar, o sea entendiendo cuáles son sus atributos y el modo de cómo estos se manifiestan, escuchando el murmullo, el rumor del lugar".

Existen zonas protegidas gracias al arrastre de semillas del caudal durante todo el año y que se ubican entre los espigones de los gaviones, donde crece vegetación de permanencia continua. El proyecto busca repetir estos espacios de gran riqueza en varios lugares estratégicos a través de una serie de intervenciones en los bordes, de manera de generar una caja de río más rugosa y un sistema de zonas protegidas. ARQ

Martín Andrade

\section{Bibliografía}

Brunet, Roger, Ferras, Robert y Hervé Théry. “Paysage”. Les mots de la géographie. Dictionnaire critique. Reclus - La Documentation française, París, 1992. | Cerda, René. "Cuando el territorio se vuelve paisaje”. CA № 131. Colegio de Arquitectos de Chile A.G., Santiago, agosto - septiembre de 2007. / De Solá Morales, Manuel. Cuatro paradigmas para un curso de ética urbanística. Los Territorios del Urbanista. Universitat Politécnica de Cataluña, Barcelona, 2005. | Moneo, Rafael. Contra de indiferencia como norma. Ediciones ARQ Santiago, 1995. / Pavez, María Isabel. "A 100 años del parque José Domingo Gómez Rojas: su restauración o su muerte”. Revista de Urbanismo № 16 . Facultad de Arquitectura, Universidad de Chile, Santiago, junio de 2007. 

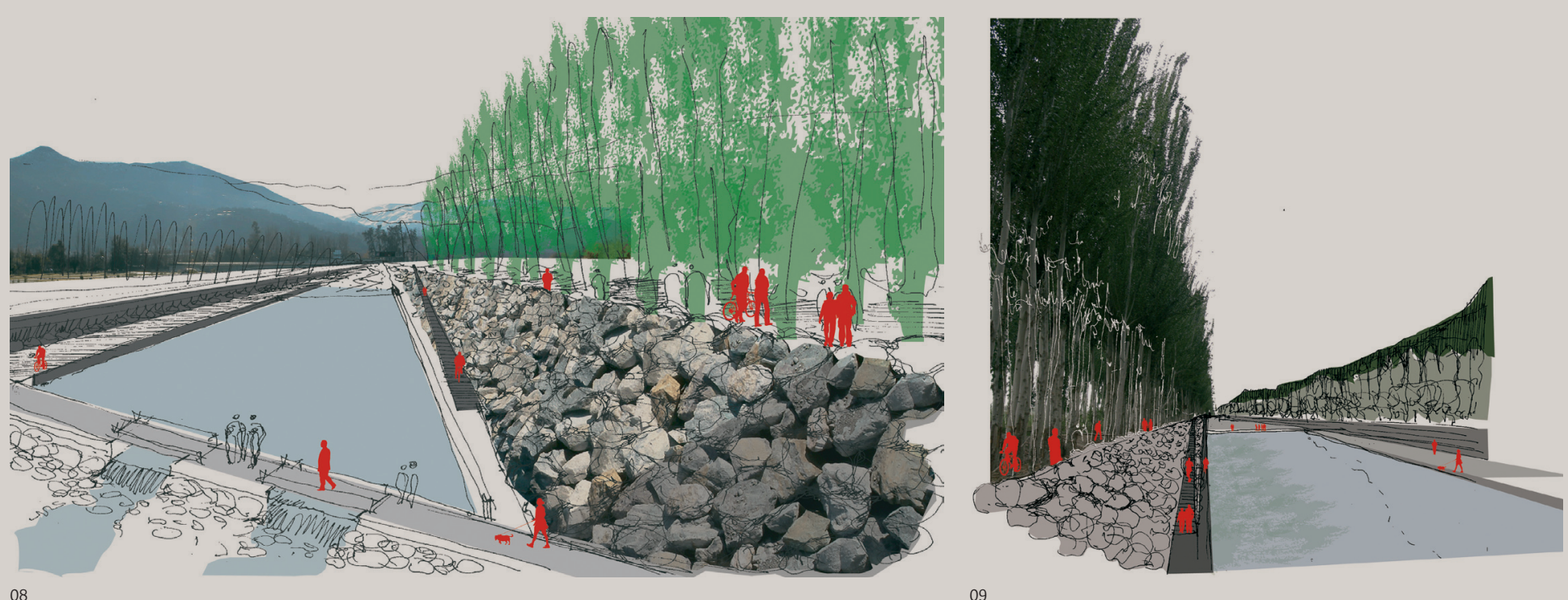

10 a 13 Martin Andrade. Plantas de capas del proyecto

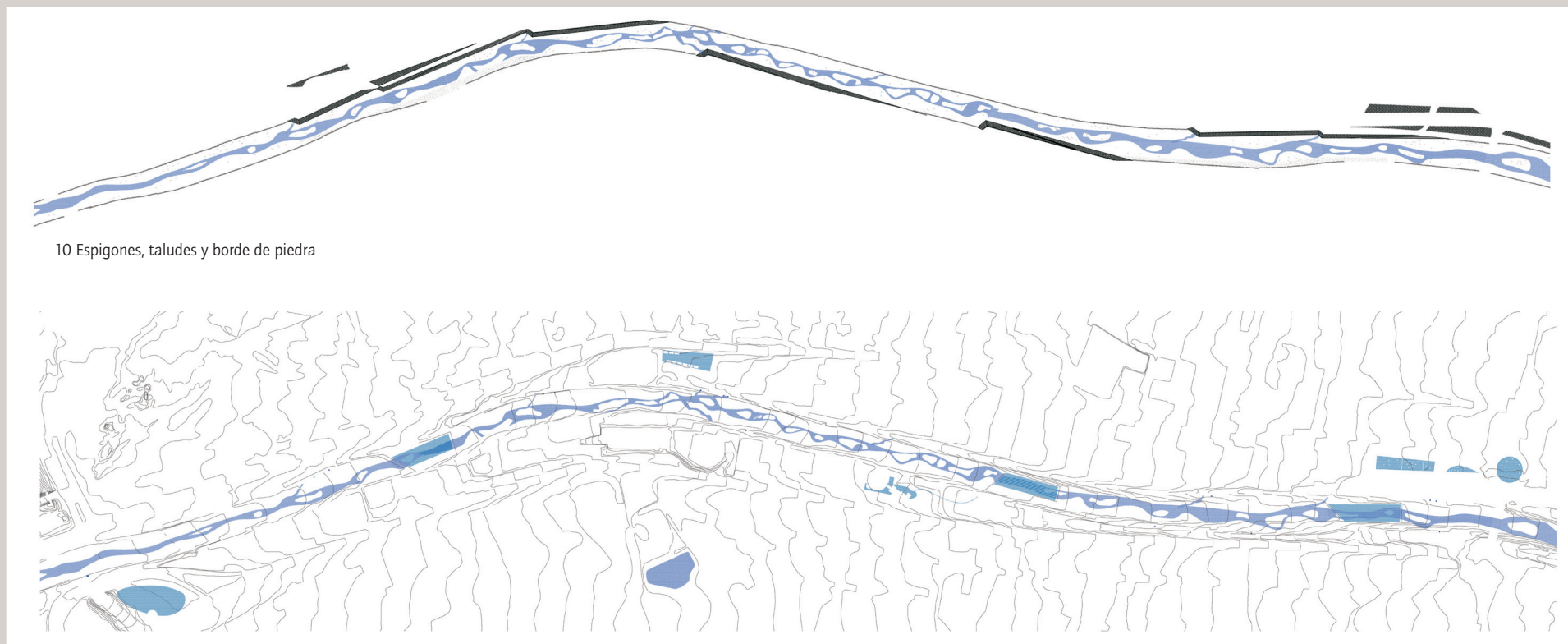

11 Curvas de nivel espejos de agua, vertederos y tranque

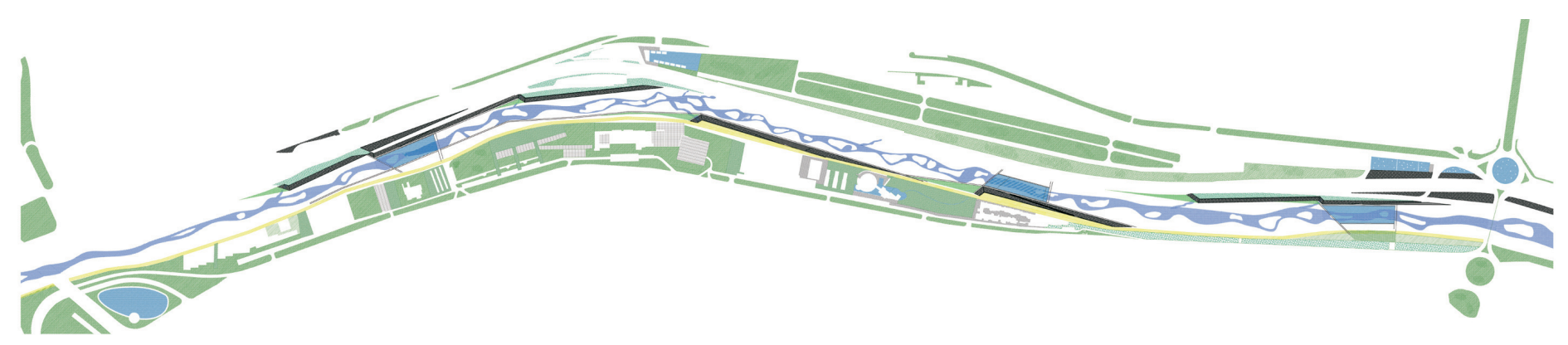

12 Tipos de superficies

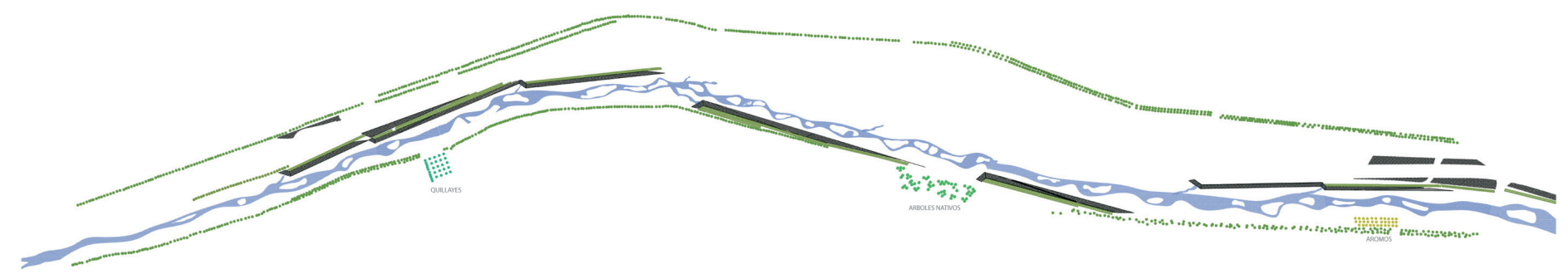

